\title{
Phagocytosis of Candida albicans in Chronic Mucocutaneous Candidiasis
}

\author{
ROBERT BORTOLUSSI, ${ }^{(24)}$ GARY FAULKNER, SPENCER H. S. LEE, AND RUDOLF OZERE \\ Department of Pediatrics, I. W. K. Hospital for Children, and Department of Microbiology, Dalhousie University, \\ Halifax, Nova Scotia, Canada
}

\section{Summary}

Inasmuch as human monocytes are able to kill Candida albicans (C. albicans) only through oxidative pathways, which also produce chemiluminescence $(\mathrm{CL}), \mathrm{CL}$ was used to assess the ability of polymorphonuclear neutrophils and monocytes to phagocytose and kill $C$. albicans in a 12-year-old girl with chronic mucocutaneous candidiasis.

In contrast to normal mononuclear cells (monocytes and lymphocytes), mononuclear cells from the patient did not respond with a $\mathrm{CL}$ burst when mixed with opsonized $C$. albicans (peak $\mathrm{CL}, 55$ versus $105 \mathrm{cpm} \times 10^{-3}$ for control). Phagocytosis of $C$. albicans by monocytes, assessed by electron microscopy, was normal. The patient's mononuclear cells did produce $\mathrm{CL}$ when mixed with Candida parapsilosis (peak CL, 68 versus $72 \mathrm{cpm} \times 10^{-3}$ for control) or zymosan (peak CL, 149 versus $180 \mathrm{cpm} \times 10^{-3}$ for control). Myeloperoxidase activity in monocytes assessed by light microscopy was normal. However, peroxidase activity in the patient's monocytes persisted in glass-adherent monocyte-macrophages after 5 days incubation, suggesting that her cells may mature poorly.

In contrast to the poor $C L$ response of monocytes to $C$. albicans, polymorphonuclear neutrophils from the patient had increased $C L$ (peak, 858 versus $458 \mathrm{cpm} \times 10^{-3}$ for control). Also, the patient's serum showed increased opsonic activity for $C$. albicans (peak, 1800 versus $1100 \mathrm{cpm} \times 10^{-3}$ for control).

\section{Speculation}

We speculate that monocytes from the patient had a defect in the release of oxidative radicals into phagosomes containing Candida albicans, or, if oxidative products were released, that these oxidative products were neutralized by $C$. albicans before $C L$ could occur. Inasmuch as the killing of $\boldsymbol{C}$. albicans by monocytes is dependent on the oxidative process, the organism may be able to survive in such cells. Survival of $C$. albicans within mononuclear cells may protect the organism from humoral or chemical fungicidal activity.

Chronic mucocutaneous candidiasis (CMC) is a disease characterized by persistent Candida albicans (C. albicans) infection of the epidermis, particularly the nails and hands, and of mucous membranes (8). At least four clinical groups of CMC have been described based on the age of the patient at onset of disease and the presence of endocrinopathy (22). Although the humoral and cellular immunity of patients with CMC have been studied extensively $(10,18,20)$, there are few reports on the function of phagocytic cells in these patients $(12,21)$. Ingestion and killing of C. albicans by polymorphonuclear leukocytes (PMNs) have been reported as normal (21) and abnormal (16). Ingestion and killing of $C$. albicans by monocytes has been studied only occasionally in these patients. As reported by Van der Meer et al. (21) using a microbiologic technique, some patients with $\mathrm{CMC}$ have defective monocyte candicidal activity. This report led us to study the PMNs and mononuclear leukocyte candicidal activity in a patient with CMC.

Lehrer (11) has shown that monocyte cidal activity for $C$. albicans is dependent on the myeloperoxidase-hydrogen peroxide system in man. Chemiluminescence (CL), the emission of light by phagocytic cells, is also dependent on the myeloperoxidase-hydrogen peroxide system. It correlates with the increased metabolic activity and the respiratory burst which occurs during phagocytosis and killing of yeast and bacteria $(3,14)$. The exact source of $\mathrm{CL}$ is not known but is probably a result of the interaction of ingested particles and of one or more oxidizing agents produced by the cell (13).

In this report, we describe one patient with $\mathrm{CMC}$ and having an abnormality of her mononuclear cell (MNC) CL which occurred during phagocytosis of $C$. albicans but not during phagocytosis of C. parapsilosis or zymosan.

\section{CASE REPORT}

An 1l-year-old girl, the fourth child of nonconsanguinous parents, was admitted to the Izaak Walton Killam Hospital for Children with an established diagnosis of chronic mucocutaneous candidiasis. Her illness began at the age of 14 months when she developed recurrent and persistent oral candidiasis followed by the development of chronic, scaling erythematous skin lesions involving her hands, fingernails, scalp, face, and eyelids. She had recurrent febrile episodes, some without any apparent focus of infection, others due to secondary staphylococcal infections of the skin and eyelids. There was no history of diarrhea, but caloric intake was poor and she had growth retardation. A maternal great aunt had a similar but less severe illness primarily involving the fingernails.

In addition to chronic mucocutaneous candidiasis, investigations on previous admissions to hospital had revealed the presence of hypothyroidism with markedly diminished $\mathrm{T}_{4}$ and $\mathrm{T}_{3}$ uptake. Tests for thyroid antibodies were negative. Serum cortisol and 24hr urine samples for cortisol excretion were normal. One year before the present admission, she had an episode of autoimmune pancytopenia associated with an increasing antibody titer to Epstein-Barr virus which resolved completely over a 1 -month period.

In the past, she had received multiple courses of topical and oral antifungal therapy including mycostatin and clotrimazole with transient improvement during treatment. She had also received intravenous miconizole and on a different occasion a prolonged course of amphotericin B. Moderate but nonsustained improvement in the oral and cutaneous lesions were observed on both occasions. In addition, therapy with transfer factor was attempted without appreciable benefit.

On examination she was an 11-year-old girl, well below the third percentile for height and weight. There were multiple scaling, erythematous skin lesions involving the scalp, the perioral area, and the hands. Diffuse candidal lesions were present in the mouth. 
The fingers were clubbed, and there was extensive involvement and deformity of the nails and nailbeds.

C. albicans was cultured from multiple sites of the skin and mouth. Thyroid function studies were normal while on L-thyroxine. Hemoglobin, white blood cell count, and differential cell count were within normal limits. The following serum concentrations were noted: IgG, $770 \mathrm{mg} / \mathrm{dl} ; \mathrm{IgM}, 140 \mathrm{mg} / \mathrm{dl} ; \mathrm{IgA}, 59 \mathrm{mg} /$ $\mathrm{dl} ; \mathrm{C}_{3}, 132 \mathrm{mg} / \mathrm{dl}$ (normal 120 to $170 \mathrm{mg} / \mathrm{dl}$ ); $\mathrm{C}_{2}, 12 \mathrm{mg} / \mathrm{dl}$ (normal, 12 to $75 \mathrm{mg} / \mathrm{dl}$ ). Skin tests to C. albicans antigen at 1/ 1000 and $1 / 100$ dilution were negative whereas skin tests to tetanus and Trichophyton were positive.

\section{MATERIALS AND METHODS}

\section{LEUKOCYTE PREPARATION}

Control and patient bloods were collected in heparinized plastic syringes (10 units heparin per $\mathrm{ml}$ blood). The mononuclear and PMN fractions were separated using the Ficoll-Hypaque gradient centrifugation as described by Boyum (2).

For the monocyte-macrophage cultures, peripheral blood monocytes were prepared and cultured as described recently (9). Briefly, monocyte enriched mononuclear cells were separated from circulating blood with Ficoll-Paque (Pharmacia Fine Chemicals, Uppsala, Sweden) gradient centrifugation. The cell concentration was adjusted to $1.2 \times 10^{6}$ monocytes $/ \mathrm{ml}$ in McCoy's $5 \mathrm{~A}$ medium (Flow Laboratories, Mississauga, Ontario, Canada) supplemented with $30 \%$ human $\mathrm{AB}$ serum. Aliquots of $0.8 \mathrm{ml}$ were dispensed into $16 \times 83 \mathrm{~mm}$ Leighton tubes (Bellco Glass, Inc., Vineland, NJ) with $10 \times 10 \mathrm{ml}$ window area, each of which contained a $9 \times 9 \mathrm{~mm}$ glass cover slip. Monocytes were isolated from the mononuclear cell suspension by adherence onto glass after incubation at $37^{\circ} \mathrm{C}$. Nonadherent cells, mainly lymphocytes, were removed by washing.

For the blastogenic response of lymphocytes to $C$. albicans antigen, lymphocytes separated from blood on Ficoll-Hypaque gradient were washed and resuspended in McCoy's 5A medium supplemented with $15 \%$ heat-inactivated fetal bovine serum (culture medium). Aliquots of $0.1 \mathrm{ml}$ containing $5 \times 10^{5}$ lymphocytes were distributed into wells of flat-bottom tissue culture cluster plate (Costar, Cambridge, MA).C. albicans allergenic extract (Hollister-Stier Labs, Mississauga, Ontario, Canada) containing 1000 $\mathrm{pnu} / 0.1 \mathrm{ml}$ was dialized overnight against 100 volumes of Hanks' balanced salt solution (HBSS; Grand Island Biological Co., Grand Island, NY) sterilized by filtration (Millipore Corp., Bedford, MA) and diluted in culture medium before use. The diluted antigen was added in 0.1 volume using four well cultures per dilution. The plates were incubated at $37^{\circ} \mathrm{C}$ in a humidified $\mathrm{CO}_{2}$ incubator with $5 \% \mathrm{CO}_{2}$ in air for 7 days. For blastogenic response to phytohemagglutinan $\mathrm{P}$ (Difco Laboratories, Detroit, MI), similar cultures were incubated with $1 / 200,1 / 400$, and $1 / 800$ dilutions of PHA-P for 3 days. Sixteen hr before termination of cultures, $0.01 \mathrm{ml}$ of $\left[{ }^{3} \mathrm{H}\right]$ thymidine diluted in McCoy's $5 \mathrm{~A}$ medium to contain $20 \mu \mathrm{Ci}$ / $\mathrm{ml}$ (specific activity, $2.1 \mathrm{Ci} /$ nmole; New England Nuclear, Boston, MA) was added to each well. The cells were harvested onto glass filter paper with an automatic Mash-harvester. The dried filter paper discs were transferred to scintillation vials to which $5 \mathrm{ml}$ of toluene-base omnifluor (New England Nuclear, Boston, MA) were added, and the samples were counted on a Nuclear Chicago isotope -300 liquid scintillation counter.

For the CL assay, MNCs (monocytes and lymphocytes) from the Ficoll-Hypaque preparation were washed in HBSS. A sample was withdrawn for counting of cells and for staining using Wright's stain. The MNCs were resuspended to a concentration or $2 \times 10^{5}$ monocytes per $\mathrm{ml}$ ( $1 \%$ contaminating PMNs were present). For the PMN suspension, the lower layer of the Ficoll-Hypaque preparation was aspirated, and contaminating red blood cells removed by lysis using a hypotonic $\mathrm{NH}_{4} \mathrm{Cl}$ red blood cell lysing solution (1). The suspension of PMNs was washed in HBSS and suspended to a concentration of $1 \times 10^{6}$. PMNs per ml.

\section{PREPARATION OF YEAST}

Two strains of $C$. albicans, one of which was isolated from the patient, and a strain of $C$. parapsilosis which were used in our studies were kindly provided by Dr. J. Wort (I. W. Killam Hospital, Halifax, Nova Scotia, Canada). Fungal cells for phagocytosis were grown at $30^{\circ} \mathrm{C}$ for 5 days in Nutrient Broth (Difco Laboratories). The yeast particles were washed two times in phosphate-buffered saline [(PBS) $\mathrm{pH} 7.4]$ and resuspended to an optical density of 0.60 at $620 \mathrm{~nm}$ (Gilford Institute Laboratories, Obertin, $\mathrm{OH}$ ) resulting in a concentration of approximately $5 \times$ $10^{8}$ particles per ml. Zymosan (Sigma Chemical Co., St. Louis, MO) was prepared as described previously (14).

Serum which was used for opsonization was collected from the patient and from controls at the time phagocytic studies were being prepared. For opsonization, two parts particle suspension and one part serum were rotated slowly at $37^{\circ} \mathrm{C}$ for $30 \mathrm{~min}$ (Labindustries, Berkeley, CA). The suspension was then centrifuged at $2000 \mathrm{rpm}$ for $15 \mathrm{~min}$, and particles were resuspended to the orginal concentration in PBS.

\section{CHEMILUMINESCENT STUDY}

$\mathrm{Cl}$ was measured at ambient temperature on a Nuclear-Chicago Mark 1 liquid scintillation counter adjusted out of coincidence. Counting vials (Fisher Scientific, Halifax, Nova Scotia, Canada) which had been dark adapted for at least $24 \mathrm{hr}$, were transferred to the scintillation counter and filled.

Duplicate counting vials containing $4.5 \mathrm{ml}$ of opsonized or unopsonized particles in HBSS were prepared. Background values for these vials were determined from counts obtained on a preliminary counting cycle. One $\mathrm{ml}$ of the PMN suspension $\left(1 \times 10^{6}\right.$ PMNs) or the mononuclear suspension $\left(2 \times 10^{5}\right.$ monocytes $)$ were then added. This provided a ratio of approximately 600 microorganisms or approximately 50 zymosan particles for each PMN or five times this amount for each monocyte. The vials were counted for $0.1 \mathrm{~min}$ every $5 \mathrm{~min}$. Results were expressed as cpm/phagocyte. Control vials containing leukocytes with unopsonized particles or leukocytes alone were included in each run. Luminol (5-amino2,3,-dihydro-1,4 -phthalazinedione; Sigma Chemical Co.) $5 \times 10^{-7}$ and $10^{-6} \mathrm{M}$ was added to PMN and monocyte vials, respectively.

\section{DEVELOPMENT OFMONOCYTES TO MACROPHAGES IN CULTURE}

The progression of monocytes to macrophages in culture was monitored on each cover slip cultured by morphologic observation as well as by peroxidase reactivity at varying periods of incubation as described recently (9). To achieve this, the culture medium was removed, and the cultures were exposed directly to Kaplow's staining mixture 20 to $30 \mathrm{~min}$ at room temperature (7). They were then washed twice in PBS and fixed in $1.25 \%$ phosphate-buffered glutaraldehyde. They were then examined under phase contrast microscopy for morphologic alterations and under light microscopy for red brown granular deposits indicative of peroxidase reactivity.

\section{ELECTRON MICROSCOPY}

Samples were fixed for 2 to $4 \mathrm{hr}$ in a solution of $2.5 \%$ glutaraldehyde at $4{ }^{\circ} \mathrm{C}$ and postfixed in $1 \%$ osmium tetroxide (Marivac Ltd., Halifax, Nova Scotia, Canada) for 2 to $4 \mathrm{hr}$ at $4^{\circ} \mathrm{C}$. The fixatives were buffered in $0.1 \mathrm{M}$ sodium cacodylate ( $\mathrm{pH} 7.3$ ). Tissues were left overnight in $0.5 \%$ aqueous uranyl acetate at $4^{\circ} \mathrm{C}$ before dehydration and embedding. Thin sections were cut on a LKB-Huxley ultratome and double-stained with $2 \%$ aqueous uranyl acetate and lead citrate. Observations were made using a Phillips 200 electron microscope.

\section{RESULTS}

\section{MATURATION OF MONOCYTES TO MACROPHAGES IN CULTURES}

Patient and control monocytes had equivalent peroxidase reactivity at the time of sampling. After 2 and 5 days of culture, both 
the control and the patient cells showed decrease in peroxidase activity (Table 1). The decrease in peroxidase activity seen with the patient's cells was less than normal and was considerably less than the control cell preparation. In addition, by day 5 , cultures of the patient's cells showed considerable less spreading than control cells.

\section{BLASTOGENIC RESPONSE OF LYMPHOCYTES TO C. ALBICANS ANTIGEN}

Blastogenic response of the patient's lymphocytes was abnormal for $C$. albicans antigen over a wide range of antigen dilutions from 1 in 16 to 1 in 128 . Blastogenic response of phytohemagglutinin, however, was normal.

\section{OPSONIC RESPONSE}

The maximum cpm indicating peak $\mathrm{CL}$, reached within 180 min of mixing control PMNs with $C$. albicans preopsonized with patient or control serum at $30 \%$ concentration, was used to compare the ability of these sera to opsonize $C$. albicans. The patient's serum repeatedly showed greater activity compared to control serum (Fig. 1). In addition patient serum had increased opsonic activity for zymosan with peak CL $900 \mathrm{cpm} \times 10^{-3}$ compared to $500 \mathrm{cpm} \times 10^{-3}$ for control serum.

\section{ACTIVITY USING PATIENT AND CONTROL PMNS}

Peak CL recorded within $180 \mathrm{~min}$ of mixing patient or control PMNs with $C$. albicans, $C$. parapsilosis, or zymosan was used to compare phagocytic and cidal activity of these cells (Table 2). In each experiment, yeast particles or zymosan were opsonized with the same control serum. Patient PMNs had significantly greater $\mathrm{CL}$ when $C$. albicans was used as the particulate source for phagocytosis $\left(858 \times 10^{-3} \mathrm{cpm}\right.$ versus $\left.458 \times 10^{-3} \mathrm{cpm} ; P<0.025\right)$. With $C$. parapsilosis and zymosan patients, PMNs had increased chemiluminescent activity compared to control cells; however, these differences were not significant.

\section{USING MNC}

MNCs from the patient had significantly less CL when mixed with opsonized $C$. albicans compared to control mononuclear cells $(P<0.005$; Fig. 2). We performed the experiment in duplicate on three occasions and obtained similar results on each occasion with strains of $C$. albicans isolated from the patient or from a person who did not have CMC. Using control MNC, CL was maximal 40 min after mixing with $C$. albicans. A CL burst was not observed when the patient's MNCs were mixed with $C$. albicans. CL increased only gradually and had not reached maximal activity until 70 min. Both peak $\mathrm{CL}$ and the time at which it occurred were significantly different for control and patient cells $(P<0.05)$.

In contrast to these studies, the patient's MNC had normal CL when mixed with opsonized $C$. parapsilosis or zymosan (Table 3 ). Both peak CL and the time at which it was achieved were similar in the patient and control MNC preparations for these particles.

Studies were done to determine if the CL activity of MNC from the patient or control could be altered by in vitro manipulation.

Although the yeast and cell preparations were washed before the $\mathrm{CL}$ studies, the possibility that minute amounts of serum could effect the results was considered. When control MNC were deliberately contaminated with small amounts of the patient's serum,

Table 1. Percent of peroxidase positive cells on Day of Culture

\begin{tabular}{lccc} 
& Day $0^{\prime}$ & Day 2 & Day 5 \\
\hline Patient & 98 & 75 & 30 \\
Control & 95 & 50 & 10 \\
\hline
\end{tabular}

\footnotetext{
' Day $0=3 \mathrm{hr}$ after seeding of culture.
}

increased CL was seen, suggesting that the patient's serum enhanced phagocytosis and the production of CL by monocytes.

It has recently been shown that monocyte phagocytic activity is altered by changes in intracellular cyclic nucleotide concentration (15). We studied MNC from the patient and a control in the presence of levamisole, a potent stimulator of cyclic guanosine $3^{\prime}, 5^{\prime}$-monophosphate production (6). When incubated for $15 \mathrm{~min}$ with levamisole $(1 \mu \mathrm{g} / \mathrm{ml})$, control MNC had increased CL activity during $C$. albicans phagocytosis. Preincubation of the patient's $\mathrm{MNC}$ with levamisole, however, did not change CL intensity (Fig. 3; levamisole; Jensen Pharmaceutica, New Brunswick, NJ).

Attempts were made to determine if the decrease in CL which was observed was due to a decrease in the phagocytic activity taking place in the MNC C. albicans mixture. Electron microscopic studies were therefore carried out. The fine structure of patient and control monocytes were normal. Approximately $35 \%$ of both patient and control MNC had intracellular C. albicans after 90 min incubation with opsonized C. albicans. C. albicans measured 3 to 6 microns, and their intracellular and extracellular morphology were similar (Fig. 4).

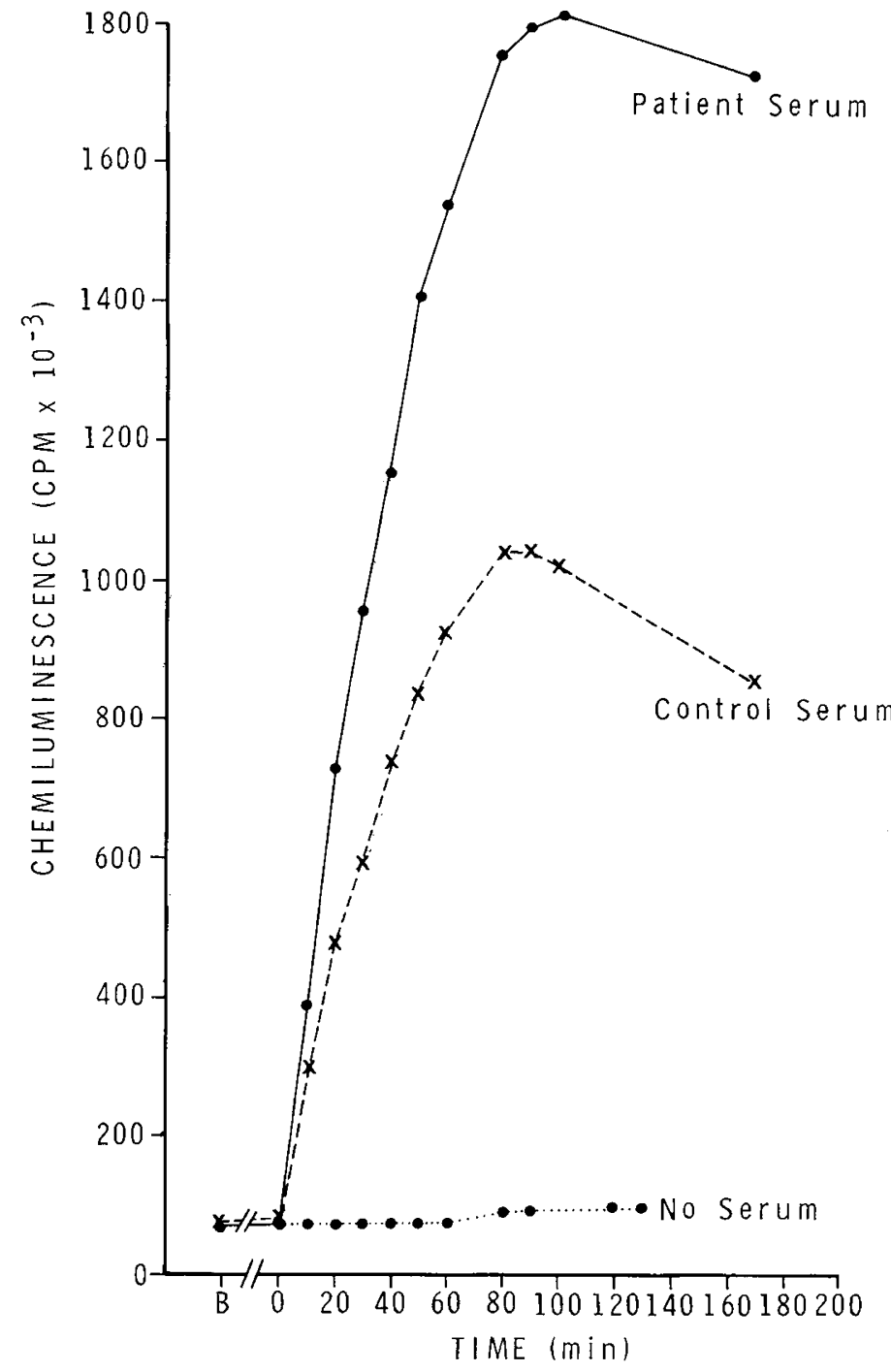

Fig. 1. Influence of donor of serum on the opsonization of C. albicans: production of CL by control PMN's mixed with C. albicans opsonized with the patient's serum $(-)$ ) or control serum $(\times)$. Reaction mixture contained $1 \times 10^{6} \mathrm{PMNs}, 6 \times 10^{8} \mathrm{cfu}$ of $C$. albicans and Luminol in HBSS. A representative study is illustrated. 
Table 2. Chemiluminescent activity using PMNs from patient or control

Chemiluminescent peak ${ }^{1}$ $(\text { time in } \min )^{2}$

\begin{tabular}{lcccc} 
& \multicolumn{2}{c}{ Patient } & \multicolumn{2}{c}{ Controls } \\
\cline { 2 - 5 } Opsonized Particle & $858^{3}$ & $(83)$ & $458^{3}$ & $(70)$ \\
Candida albicans & 309 & $(75)$ & 119 & $(85)$ \\
Candida parapsilosis & 1439 & $(12)$ & 892 & $(10)$ \\
Zymosan &
\end{tabular}

${ }^{1} \mathrm{cpm} \times 10^{-3}$ using $1 \times 10^{6} \mathrm{PMN}$ per test.

${ }^{2}$ Time in minutes at which peak CL activity was observed.

${ }^{3}$ Patient and control significantly different; $P<0.025$.

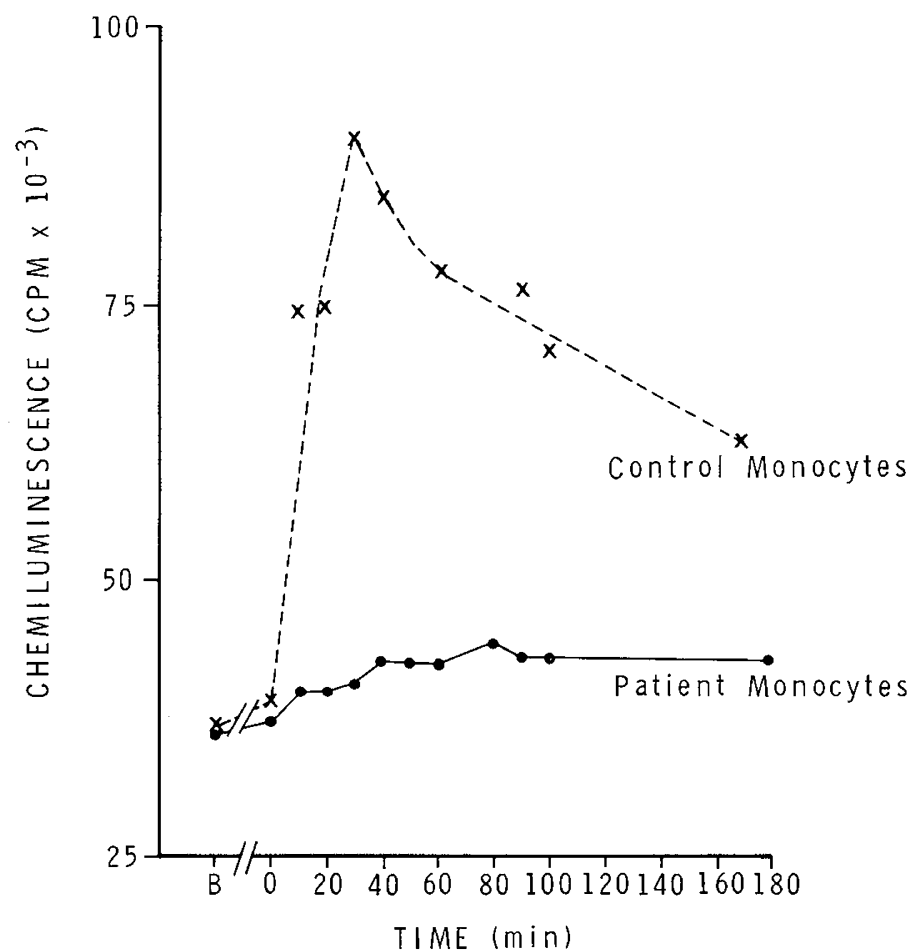

Fig. 2. Production of $\mathrm{CL}$ by monocytes as MNCs after phagocytosis of C. albicans. Counting vials contained Luminol, $2 \times 10^{5}$ monocytes, and 6 $\times 10^{8} \mathrm{cfu}$ of C. albicans opsonized with serum from the patient. Upper tracing, control monocytes; lower tracing, patient monocytes. A representative study is illustrated.

Table 3. Chemiluminescent activity using mononuclear cells from patient or control

\begin{tabular}{lcccc}
\hline & \multicolumn{4}{c}{$\begin{array}{c}\text { Chemiluminescent peak } \\
\text { (time in min) }\end{array}$} \\
\cline { 2 - 5 } \multicolumn{1}{c}{ Opsonized particle } & \multicolumn{3}{c}{ Patient } & \multicolumn{2}{c}{ Controls } \\
\hline Candida albicans & $55^{3}$ & $(71)^{4}$ & $105^{3}$ & $(39)^{4}$ \\
Candida parapsilosis & 68 & $(55)$ & 72 & $(44)$ \\
Zymosan & 149 & $(20)$ & 180 & $(20)$ \\
\hline
\end{tabular}

${ }^{1} \mathrm{cpm} \times 10^{-3}$ using $2 \times 10^{5}$ monocytes per test.

${ }^{2}$ Time in minutes at which peak $\mathrm{CL}$ activity was observed.

${ }^{3}$ Patient and control CL peak; $P<0.005$

${ }^{4}$ Patient and control time at peak CL; $P<0.005$.

\section{DISCUSSION}

The interaction of phagocytic cells and $C$. albicans can be divided into two stages: ingestion, an energy-requiring process, and killing, a process that requires the oxidative products of myeloperoxidase-hydrogen peroxide. The primary functional de-

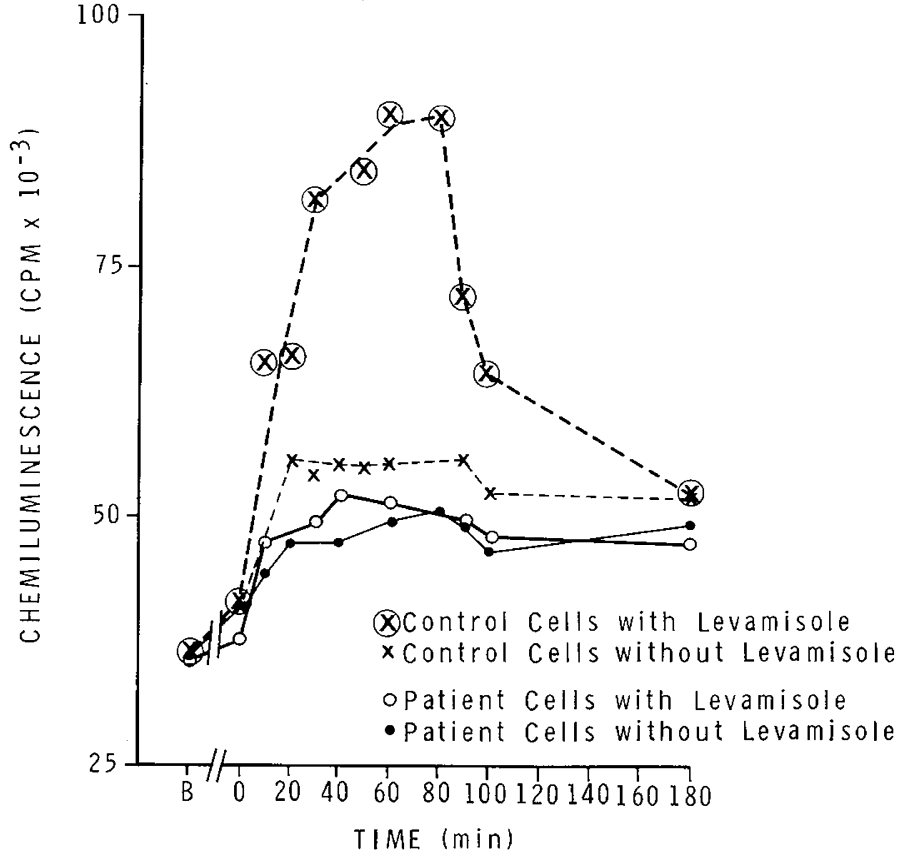

Fig. 3. Production of CL by monocytes after phagocytosis of $C$. albicans preopsonized in control serum. Treatment of control monocytes with levomisole $(\otimes)$ increases $C L$ above baseline for control monocytes $(X)$, whereas treatment of the patient's monocytes with levamisole did not alter $\mathrm{CL}$ response of untreated patient monocytes (-). CL was less than in Figure 2 because a less active serum was used to opsonize the organism.

fect in our patient's cells appears to be the inability of the MNCs to respond with an oxidative burst after phagocytosis of C. albicans blastospheres. This defect is unlikely to be due to an abnormality in phagocytosis because ingested C. albicans blastospsheres were seen within the patient's MNCs by electronmicroscopic examination. In addition, levamisole, a potent stimulator of phagocytosis failed to alter the response of the patient's mononuclear cells to $C$. albicans after in vitro incubation (15). CL with patient MNCs and C. albicans however, was grossly abnormal. CL is dependent on the oxidative burst which occurs during phagocytosis and is primarily produced by myeloperoxidase-hydrogen peroxide interaction (3). Myeloperoxidase was present in the patient's monocytes. CL for other particles, Zymosan or C. parapsilosis, was only marginally less than controls, suggesting peroxidase-hydrogen peroxide interaction occurs when $C$. albicans is not present. $C$. albicans, unlike other Candida species, is dependent on the peroxidase-hydrogen peroxide system for killing (11).

The defect in CL was not found with PMNs from the patient. Indeed, the $\mathrm{CL}$ response to $C$. albicans in these cells was increased. Some investigators have found phagocytosis and killing of $C$. albicans using PMNs from patients with CMC to be normal (21) whereas others have found it to be decreased (16). Our results suggested that PMNs from our patient had increased activity for phagocytosis and killing of $C$. albicans.

The maturation of the patient monocytes, assessed by glass spreading and peroxidase activity after in vitro incubation was abnormal, suggested that her circulating monocytes were immature or unable to transform into macrophages under in vitro conditions. The blastogenic response of her MNCs to C. albicans was also abnormal. Inasmuch as monocytes enhance this response, this observation may also suggest an abnormality in monocyte function (4).

Hilger and Danley (5) have demonstrated that live blastospheres of C. albicans appear to inhibit $\mathrm{H}_{2} \mathrm{O}_{2}$ release by normal human PMNs. This effect was not seen with killed blastospheres. No alteration in $\mathrm{CL}$ was found in these studies. Tomioka and Saito have recently shown that conconavalin A (Con A) exhibited an 


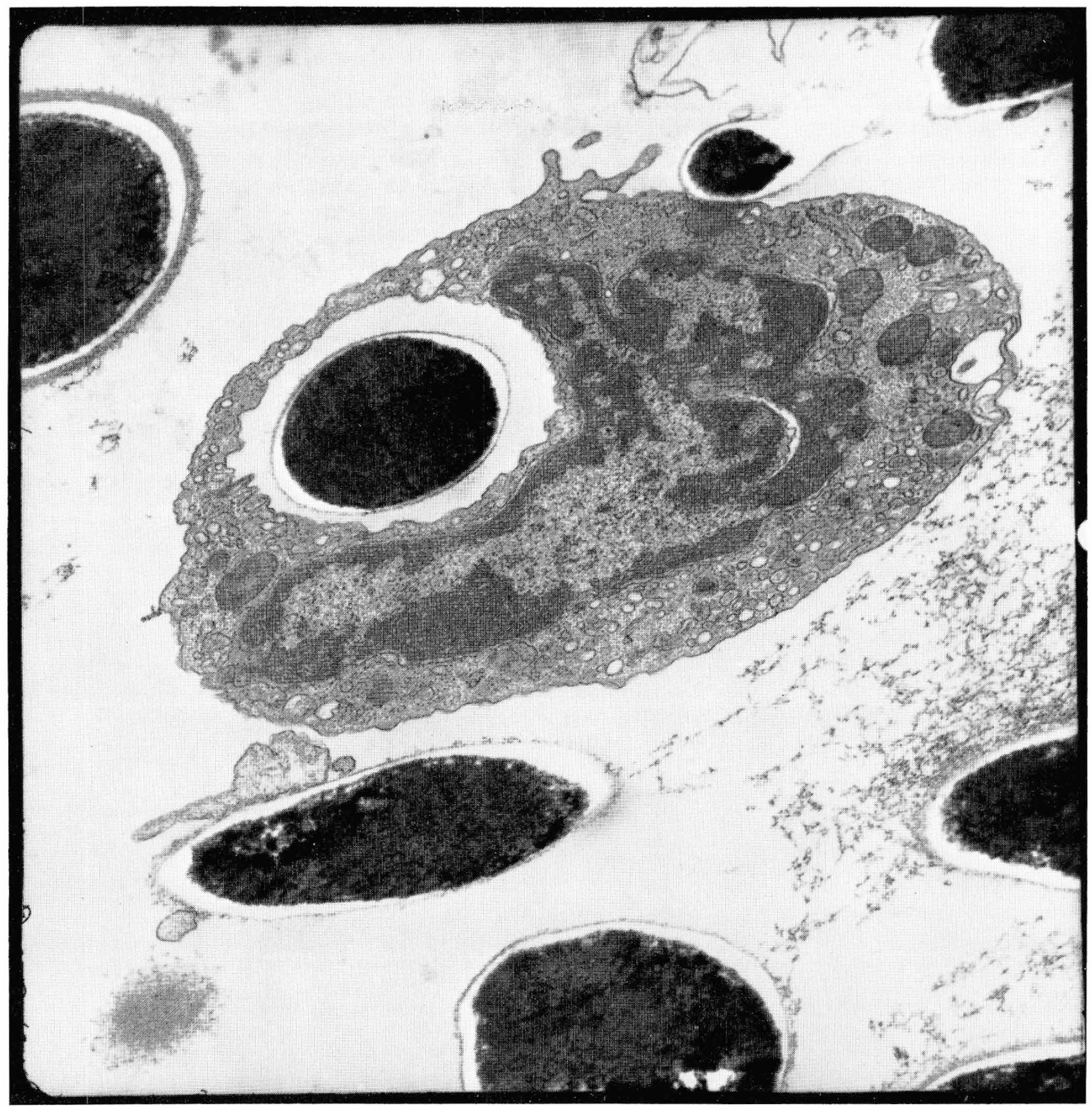

Fig. 4. Electron micrograph of patient mononuclear cell after $90 \mathrm{~min}$ incubation with opsonized C. albicans $\times 21700$.

inhibitory action on macrophage $\mathrm{H}_{2} \mathrm{O}_{2}$ release (19). Con A had no effect on the release of $\mathrm{H}_{2} \mathrm{O}_{2}$ from PMNs. The effects of Con $A$ were attributed to its inhibitory action on macrophage $\mathrm{H}_{2} \mathrm{O}_{2}$ release by specific binding to D-mannopyranoside receptor sites on the macrophage cell surface. It is interesting that $C$. albicans, like other Candida species, is rich in mannon protein complexes and mannose polysaccharide (17).

We speculate that the release of oxidative products and increase in CL may be inhibited in our patient's monocytes by capsular products present on $C$. albicans but not present on C. parapsilosis or zymosan. In view of this evidence, it seems reasonable to postulate that a cidal defect resulted from the failure of the patient's MNCs to respond with an oxidative burst to C. albicans.

\section{REFERENCES AND NOTES}

1. Andersen, B. R., and Amirault, H. J.: Important variables in granulocyte chemiluminescence (40633). Proc. Soc. Exp. Biol. Med., 162: 139 (1979).
2. Boyum, A.: Isolation of mononuclear cells and granulocytes from human blood. Isolation of mononuclear cells by one centrifugation, and of granulocytes by combining centrifugation and sedimentation at $1 \mathrm{~g}$. Scand. J. Clin. Lab. Invest., 97: 77 (1968).

3. Cheson, B. D., Christensen, R. L., Sperling, R., Kohler, B. E., and Babior, B. M. The origin of the chemiluminenscence of phagocytosing granulocytes. J. Clin. Invest., 58: 789 (1976).

4. De Vries, J. E., Caviles, A. P., Willy, S. B., and Mendelsohn, J.: The role of monocytes in human lymphocyte activation by mitogens. J. Immunol., 122: 1099 (1979).

5. Hilger, A. E., and Danley, D. L.: Alteration of polymorphonuclear leukocyte activity by viable Candida albicans. Infect. Immun., 27: 714 (1980).

6. Hogan, N. A., and Hill, H. R.: Enhancement of neutrophil chemotaxis and alteration of levels of cellular cyclic nucleotides by levamisole. J. Infect. Dis., 138: 437 (1978).

7. Kaplow, L. S.: Substitute for benzidine in myeloperoxidase stains. Am. J. Clin. Pathol., 63: 451 (1975).

8. Kirkpatrick, C. H., Rich, R. R., and Bennett, J. E.: Chronic mucocutaneous candidiasis: model-building in cellular immunity. Ann. Intern. Med., 74: 955 (1971).

9. Lee, S. H. S., and Epstein, L. B.: Reversible inhibition by interferon of the 
maturation of human peripheral blood monocytes to macrophages. Cell. Immunol.. 50: 177 (1980).

10. Lehner, T., Wilton, J. M. A., and Ivanyi, L.: Immunodeficiencies in chronic muco-cutaneous candidiasis. Immunology, 22: 775 (1972).

11. Lehrer, R. I.: The fungicidal mechanisms of human monocytes 1 . Evidence for myeloperoxidase-linked and myeloperoxidase-independent candidacidal mechanisms. J. Clin. Invest., 55: 338 (1975).

12. Lehrer, R. I.: Host defense mechanisms against disseminated Candidiasis. Ann Intern. Med.. 89: 91 (1978)

13. McPhail, L. C.. DeChatelet, L. R., and Johnston, R. B., Jr.: Generation of chemiluminescence by a particulate fraction isolated from human neutrophils. J. Clin. Invest., 63: 648 (1979).

14. Nelson, R. D., Mills, E. L., Simmons, R. L., and Quie, P. G.: Chemiluminescence response of phagocytizing human monocytes. Infect. Immun., 14: 129 (1976).

15. O'Dorisio, M. S., Vandenbark. G. R., and LoBuglio, A. F.: Human monocyte killing of Staphylococcus aureus: modulation by agonists of cyclic adenosine 3', 5'-monophosphate. Infect. Immun. 26: 604 (1979)

16. Quie, P.G., and Chilgren, R. A.: Acute disseminated and chronic mucocutaneous candidiasis. Semin. Hematol., 8: 227 (1971).

17. Ray, T. L.. Hanson A., Ray, L., and Wuepper, K. D.: Purification of a mannan from Candida albicans which activated serum complement. J. Invest. Dermatol. 73 : 269 (1979).

Copyright (C) 1981 International Pediatric Research Foundation, Inc. $0031-3998 / 81 / 1509-1287 \$ 02.00 / 0$
18. Takeya, K., Nomoto, K., Matsumoto, T., Miyake, T., and Himeno, K.: Chronic mucocutaneous candidiasis accompanied by enhanced antibody production. Clin. Exp. Immunol., 25: 497 (1976).

19. Tomioka, H., and Saito, H.: Effects of some plant lectins on hydrogen peroxide release from macrophages induced with streptococcal preparation OK-432. Infect. Immun., 28: 336 (1980).

20. Valdimarsson, H., Higgs, J. M., Wells, R. S., Yamumura, M., Hobbs, J. R., and Holt. P. J. L. Immune abnormalities associated with chronic mucocutaneous candidiasis. Cell. Immunol., 6: 348 (1973).

21. Van der Meer, J. W. M., Leijh, P. C. J., Van den Barselaar, M., and Van Furth, R.: Functions of phagocytic cells in chronic mucocutaneous candidiasis. $\mathrm{Br}$. Med. J., 21: 147 (1978).

22. Wells, R. S., Higgs, J. M., MacDonald, A., Valdimarsson, H., and Holt, P. J. L.: Familial chronic muco-cutaneous candidiasis. J. Med. Genet., 9: 302 (1972).

23. The authors wish to express our thanks to JoAnne Cunningham for her expert technical assistance.

24. Requests for reprints should be addressed to: R. Bortolussi, I. W. Killam Hospital, University Ave., Halifax, Nova Scotia, Canada, B3J 3G9.

25. This research was supported in part by a grant from the Medical Research Council of Canada No. 210.

26. Received for publication October $31,1980$.

27. Accepted for publication February 2, 1981. 